\title{
Rhythmic Bursting in the Cortico-Subthalamo-Pallidal Network during Spontaneous Genetically Determined Spike and Wave Discharges
}

\author{
Jeanne Tamar Paz, Jean-Michel Deniau, and Stéphane Charpier \\ Institut National de la Santé et de la Recherche Médicale U114, Chaire de Neuropharmacologie, Collège de France and U667, 75231 Paris Cedex 05, France
}

\begin{abstract}
Absence seizures are characterized by impairment of consciousness associated with bilaterally synchronous spike-and-wave discharges (SWDs) in the electroencephalogram (EEG), which reflect paroxysmal oscillations in thalamocortical networks. Although recent studies suggest that the subthalamic nucleus (STN) provides an endogenous control system that influences the occurrence of absence seizures, the mechanisms of propagation of cortical epileptic discharges in the STN have never been explored. The present study provides the first description of the electrophysiological activity in the cortico-subthalamo-pallidal network during absence seizures in the genetic absence epilepsy rats from Strasbourg, a well established model of absence epilepsy. In corticosubthalamic neurons, the SWDs were associated with repetitive suprathreshold depolarizations correlated with EEG spikes. These cortical paroxysms were reflected in the STN by synchronized, rhythmic, high-frequency bursts of action potentials. Intracellular recordings revealed that the intraburst pattern in STN neurons was sculpted by an early depolarizing synaptic potential, followed by a short hyperpolarization and a rebound of excitation. The rhythmic hyperpolarizations in STN neurons during SWDs likely originate from a subpopulation of pallidal neurons exhibiting rhythmic bursting temporally correlated with the EEG spikes. The repetitive discharges in STN neurons accompanying absence seizures might convey powerful excitation to basal ganglia output nuclei and, consequently, may participate in the control of thalamocortical SWDs.
\end{abstract}

Key words: absence epilepsy; basal ganglia; burst firing; corticosubthalamic neurons; in vivo; subthalamic neurons

\section{Introduction}

Absence epilepsy is a generalized, nonconvulsive epilepsy of multifactorial genetic origin (Panayiotopoulos, 1997; Crunelli and Leresche, 2002). Absence seizures consist of a brief, sudden impairment of consciousness concomitant with bilateral synchronized spike-and-wave discharges (SWDs) in the electroencephalogram (EEG) over wide cortical areas (Panayiotopoulos, 1997). Electrophysiological recordings in patients (Williams, 1953) and animal models of absence epilepsy (for review, see Danober et al., 1998; Crunelli and Leresche, 2002; Timofeev and Steriade, 2004) show that SWDs result from abnormal synchronized oscillations in thalamocortical networks. A number of studies performed in genetic absence epilepsy rats from Strasbourg (GAERS), a well established genetic model of absence epilepsy (Marescaux et al., 1992; Danober et al., 1998), suggest that the basal ganglia provides an endogenous control system for absence seizures via a modulation of the glutamatergic subthalamonigral pathway (for review, see Danober et al., 1998; Deransart et al., 1998, 2002).

Received Nov. 16, 2004; revised Jan. 7, 2005; accepted Jan. 8, 2005.

This work was supported by the Ministère Français de la Recherche. We are grateful to Drs. S. Mahon and R. Miles for thoughtful discussion and critical reading of this manuscript. We also thank Dr. P. Mailly for neuronal 3-D reconstruction and A. Menetrey for assistance with the histological processing.

Correspondence should be addressed to J. T. Paz, Institut National de la Santé et de la Recherche Médicale U114 Chaire de Neuropharmacologie, Collège de France, 11 Place Marcelin Berthelot, 75231 Paris Cedex 05, France. E-mail: jeanne.paz@college-de-france.fr.

DOl:10.1523/JNEUROSCI.4689-04.2005

Copyright $\odot 2005$ Society for Neuroscience $\quad$ 0270-6474/05/252092-10\$15.00/0
Specifically, alteration of the excitatory synaptic influence of the subthalamic nucleus (STN) on the substantia nigra pars reticulata (SNr), either by bilateral injection of a GABA agonist in the STN or a blockade of nigral glutamatergic NMDA receptors, has been shown to suppress absence seizures (Deransart et al., 1996). Furthermore, either bilateral excitotoxic lesions or highfrequency stimulation of the STN dramatically affects the occurrence of cortical paroxysms in GAERS (Vercueil et al., 1998). Consistent with the antiepileptic effect of an interruption of the excitatory subthalamonigral transmission, intranigral injection of $\mathrm{GABA}_{\mathrm{A}}$ receptor antagonists increases the occurrence of SWDs in GAERS (Danober et al., 1998; Deransart et al., 1998). Together, these findings suggest that the occurrence of absence seizures is modulated by changes in the activity of subthalamonigral neurons.

STN neurons integrate powerful monosynaptic glutamatergic inputs originating from corticosubthalamic (CSth) neurons and relay these excitatory signals to the $\mathrm{SNr}$ and the globus pallidus (GP) (Deniau et al., 1978; Van Der Kooy and Hattori, 1980; Kitai and Deniau, 1981; Afsharpour, 1985; Rouzaire-Dubois and Scarnati, 1987; Maurice et al., 1998; Magill et al., 2000). GABAergic neurons of the GP shape the activity of STN neurons by a disinhibitory mechanism involving corticostriatal and striatopallidal pathways (Maurice et al., 1998; Bevan et al., 2002b) and via reciprocal connections with the STN (Magill et al., 2000; Bevan et al., 2002b). Recent studies indicate that rhythmic activity in the cerebral cortex can promote oscillations in STN and GP, the 
phase relationships of which are controlled by the reciprocal excitatory and inhibitory connections between these two nuclei (Plenz and Kitai, 1999; Magill et al., 2000, 2001; Bevan et al., 2002b).

The effect of cortical SWDs on the activity of STN neurons remains unknown, and the electrical events occurring in corticosubthalamo-pallidal networks during absence seizures have never been studied. Because these questions are crucial to our understanding of how the basal ganglia influence absence seizures, we examined in vivo in GAERS the intracellular and/or extracellular activity of CSth neurons, STN neurons, and GP neurons simultaneously with the spontaneous SWDs occurring in the EEG of the functionally related cortical region.

\section{Materials and Methods}

All experiments were performed in accordance with local Ethical Committee and European Union guidelines (directive 86/609/European Economic Community), and every precaution was taken to minimize stress and the number of animals used in each series of experiments.

Animal preparation. Experiments were performed in vivo on 24 adult (3-12 months of age) rats from the GAERS strain. Animals were anesthetized initially with sodium pentobarbital ( $40 \mathrm{mg} / \mathrm{kg}$, i.p.; Sanofi, Libourne, France) and ketamine $(100 \mathrm{mg} / \mathrm{kg}$, i.m.; Imalgène, Rhone Mérieux, France). A cannula was inserted into the trachea, and the animal was placed in a stereotaxic frame. Wounds and pressure points were (every $2 \mathrm{~h}$ ) infiltrated repeatedly with lignocaine (2\%). Once the surgical procedures had been completed (see below), ear bars were removed, and the head was held via a metallic rod cemented to the skull. Rats were maintained subsequently in a narcotized and sedated state by injections of fentanyl ( $4 \mu \mathrm{g} / \mathrm{kg}$, i.p.; Janssen-Cilag, Issy-Les-Moulineaux, France), repeated every 20-30 min (Simons and Carvell, 1989; Pinault et al., 1998; Charpier et al., 1999; Slaght et al., 2002a, 2004; Bruno et al., 2003). To obtain long-lasting stable intracellular recordings, rats were immobilized with gallamine triethiodide ( $40 \mathrm{mg}$, i.m.; every 2 h; Specia, Paris, France) and artificially ventilated. The degree of anesthesia was assessed by continuously monitoring the EEG and heart rate, and additional doses of fentanyl were administered at the slightest change toward a waking pattern (i.e., an increase in the frequency and reduction in amplitude of EEG waves and/or an increase in the heart rate). Body temperature was maintained $\left(36.5-37.5^{\circ} \mathrm{C}\right)$ with a homeothermic blanket. At the end of the experiments, animals received an overdose of sodium pentobarbital (200 $\mathrm{mg} / \mathrm{kg}$, i.p.).

Electrophysiological recordings. EEG recordings were obtained with a low-impedance $(\approx 60 \mathrm{~K} \Omega$ ) silver electrode placed on the dura above the orofacial motor cortex (12.5 $\mathrm{mm}$ anterior to the interaural line; $3.5-4$ $\mathrm{mm}$ lateral to the midline) (Hall and Lindholm, 1974; Neafsey et al., 1986; Paxinos and Watson, 1986), and the reference electrode was placed in the muscle on the opposite side of the head.

Intracellular recordings were performed using glass micropipettes filled with $2 \mathrm{M}$ potassium acetate $(40-70 \mathrm{M} \Omega)$. Measurements of apparent membrane input resistance and time constant were based on the linear electrical cable theory applied to an idealized isopotential neuron (Rall, 1969). The voltage-current $(V-I)$ relationship was measured from variations of the membrane potential in response to intracellular injections of hyperpolarizing current pulses $(-0.2$ to $-1.2 \mathrm{nA} ; 100 \mathrm{~ms}$ duration; every $1.55 \mathrm{~s} ; n \geq 6$ ) applied through the recording electrode. Apparent input resistance was assessed by measurement of the slope of the linear portion of the $V-I$ curve. The membrane time constant, assessed from $-0.4 \mathrm{nA}$ current pulses, was the time taken for the membrane potential to reach $63 \%$ of its final value. The values of membrane potential were corrected according to the tip potential recorded extracellularly immediately after termination of the intracellular recording.

For single-unit extracellular recordings and juxtacellular labeling (see below), glass electrodes were filled with $0.5 \mathrm{M} \mathrm{NaCl}$ and $1.7 \%$ neurobiotin (15-20 M $\Omega$; Vector Laboratories, Burlingame, CA).

Cortical cells, located in the orofacial motor cortex, were recorded within $300 \mu \mathrm{m}$ of the EEG electrode at the following coordinates: 12.5 $\mathrm{mm}$ anterior to the interaural line, 3-3.8 $\mathrm{mm}$ lateral to the midline, and 1491-2025 $\mu \mathrm{m}$ below the cortical surface. They were electrophysiologically identified as CSth neurons by their antidromic activation by electrical stimulation within the ipsilateral STN $(5.1-5.4 \mathrm{~mm}$ anterior to the interaural line, $2.5-2.7 \mathrm{~mm}$ lateral to the midline, and $7.3-7.6 \mathrm{~mm}$ ventral to the brain surface). STN stimuli used to test antidromic activation (200 $\mu$ s duration; 2-27 V) were applied with a bipolar concentric electrode (NE-100; Rhodes Medical Instruments, Woodland Hills, CA). To ensure correct positioning of the stimulating electrode in the STN, multiunit responses to whiskers stimulation were recorded through the stimulating electrode (Maurice et al., 2003). The criteria used to identify antidromic action potentials were: (1) a constant latency of antidromic responses despite imposed changes of membrane potential, (2) collision of antidromic spikes with spontaneously occurring orthodromic action potentials, and (3) the all-or-none property of the evoked spikes when the stimulation was just below threshold for antidromic activation.

Intracellular, single-unit and multiunit extracellular recordings in the STN were obtained from the subthalamic projection field of the orofacial motor cortex (Kolomiets et al., 2001). The corresponding stereotaxic coordinates were $4.9-5.4 \mathrm{~mm}$ anterior to the interaural line, $2.4-2.8 \mathrm{~mm}$ lateral to the midline, and 7042-7962 $\mu \mathrm{m}$ ventral to the brain surface. Extracellular recordings from GP neurons were obtained at the following coordinates: $7.6-8.1 \mathrm{~mm}$ anterior to the interaural line, $3-3.7 \mathrm{~mm}$ lateral to the midline, and 5025-6724 $\mu \mathrm{m}$ ventral to the brain surface.

In all experiments, the intracellular or single-unit and multiunit extracellular recordings were simultaneously performed with the corresponding ipsilateral cortical EEG.

Morphological identification. Extracellularly recorded neurons were labeled by juxtacellular injection of neurobiotin (Pinault, 1996; Mailly et al., 2003). Briefly, positive current pulses (1-8 nA; $200 \mathrm{~ms}$ ) were applied at a frequency of $2.5 \mathrm{~Hz}$ through the bridge circuit of the amplifier. The current was slowly increased while the electrode was advanced toward the neuron in $1 \mu \mathrm{m}$ steps (LSS-1000 Inchworm Motor Positioning System; Burleigh Instruments, Fishers, NY) until the cell discharge was driven by the injected current (see Fig. 3A2, inset). Current pulses were applied for a $10-15 \mathrm{~min}$ period to obtain a reliable labeling of neuronal processes. For intracellular recordings, depolarizing current pulses $(0.2-1 \mathrm{nA} ; 100-200 \mathrm{~ms})$ were applied at a frequency of $2.5 \mathrm{~Hz}$ at the end of the recording period. The histochemical methods used to reveal the morphology of neurobiotin-filled neurons were described in detail previously (Slaght et al., 2002a). The position of labeled neurons within the structures was confirmed using the atlas of Paxinos and Watson (1986).

Three-dimensional neuronal reconstruction. Soma, dendrites, and axons of some STN neurons were precisely drawn under $25-63 \times$ oil immersion objectives and plotted in three dimensions using the video computer Neurolucida system (MicroBrightField, Colchester, VT). Threedimensional (3-D) models of neurons were visualized using Lightwave software (Newtek, San Antonio, TX) as described previously by Mailly et al. (2001). 3-D reconstructed models of neurons could be rotated around the $x$-, $y$-, and $z$-axes, and the sources of light and camera were adjusted to enhance the $3-\mathrm{D}$ appearance of reconstructed neurons in twodimensional images (see Fig. 3A2).

Data acquisition and analysis. Intracellular records were obtained under current-clamp conditions using the active bridge mode of an Axoclamp-2B amplifier (Axon Instruments, Union City, CA). Data were stored on-line on a DRA 800 digital tape recorder (Biologic, Claix, France) and then digitized with a sampling rate of $20 \mathrm{kHz}$ (intracellular signals), $10 \mathrm{kHz}$ (extracellular signals), or $300 \mathrm{~Hz}$ (EEG) for off-line analysis. To perform spectral analysis of EEG potentials, fast Fourier transforms were applied using Spike 2 (CED Software; Cambridge Electronic Design, Cambridge, UK). Cross-correlograms of the firing between two simultaneously recorded units were obtained by first encoding the position of the peak of the action potentials into separate channels using the memory buffer function of Spike 2; the event correlation function of Spike 2 was then used to produce the cross-correlogram. The amplitude of action potentials was calculated as the potential difference between their voltage threshold, measured as the membrane potential at which the $d V / d t$ exceeded $10 \mathrm{~V} \cdot \mathrm{s}^{-1}$ (Mahon et al., 2003) and the peak of the waveform. Numerical values are given as means \pm SEM unless stated 
otherwise. Statistical significance was assessed by performing a one-way ANOVA. In some measurements, the normality of distributions was tested using the Kolmogorov-Smirnov test, and a Gaussian-Laplace fit was performed. Statistical analysis and curve fitting were performed with Origin 7.0 (Microcal Software, Northampton, MA).

\section{Results}

\section{Properties of SWDs}

The SWDs $(n=1303)$ recorded in the present study had a mean duration of $5.7 \pm 0.2 \mathrm{~s}$ (from 0.8 to $129.5 \mathrm{~s}$ ) and recurred once every $22.6 \pm 1.2 \mathrm{~s}$. The intraSWD frequency, revealed by spectral analysis of the EEG signal, ranged from 7 to 9.7 $\mathrm{Hz}(7.9 \pm 0.1 \mathrm{~Hz})$ (Fig. 1D). These temporal properties of SWDs, as well as the shape of individual spike-wave complexes, are similar to those described previously under analogous experimental conditions (Pinault et al., 1998; Charpier et al., 1999; Slaght et al., 2002a,b, 2004; Pinault, 2003) and in freely moving GAERS (Marescaux et al., 1992; Deransart et al., 2003).

\section{Intracellular activity of CSth neurons}

We recorded from CSth neurons $(n=7$ from six GAERS) located in the orofacial motor cortex. The depth of intracellular recordings, between 1491 and $2025 \mu \mathrm{m}$ from the cortical surface, suggested that CSth neurons were located in the deep part of layer V (Hall and Lindholm, 1974), a laminar localization that is consistent with previous findings obtained from anterograde and retrograde labeling of rat CSth neurons (Orieux et al., 2002). CSth neurons were identified electrophysiologically by antidromic activation after electrical stimulation of the ipsilateral STN (Fig. 1A). Antidromic latencies ranged between 1.1 and $3 \mathrm{~ms}(1.6 \pm 0.2 \mathrm{~ms} ; n=7$ cells) (Fig. $1 A$ ), consistent with the fast $(2-4 \mathrm{~ms})$ orthodromic activation of STN neurons in response to motor cortex stimulation (Kitai and Deniau, 1981; Kolomiets et al., 2001). The passive membrane properties of CSth neurons, measured during interictal periods, included a membrane potential of $-61.3 \pm 0.7$ (from -64 to $-59.2 \mathrm{mV} ; n=7$ cells) (Figs. $1 B 1, C, 2 A 1, A 2)$ and a membrane time constant of $13 \pm 0.8 \mathrm{~ms}$ (range, $9.2-15.8 \mathrm{~ms} ; n=7$ cells) (Fig. 1 B1). The apparent input resistance, measured from the slope of the linear $V-I$ curve (Fig. 1 B2), was $18.5 \pm 1.2 \mathrm{M} \Omega$ (from 15 to $24.1 \mathrm{M} \Omega ; n=7$ cells). In five CSth neurons, the firing pattern evoked by intracellular injection of suprathreshold current pulses was characteristic of "regular-spiking" neocortical neurons (Fig. 1 B1) (Connors and Gutnick, 1990; Steriade, 2004). The two remaining cells exhibited the firing mode of the "intrinsic-bursting" neocortical neurons. The firing frequencycurrent $(F-I)$ relationship, which followed a sigmoidal function (Fig. 1 B2), indicated that CSth neurons reached a maximal firing rate of $78.3 \pm 20.4 \mathrm{~Hz}$ (SD, from 50 to $100 \mathrm{~Hz} ; n=6$ cells) in response to current pulses of $+0.8 \mathrm{nA}$. In most CSth neurons (six of seven cells), large-amplitude hyperpolarizing current pulses
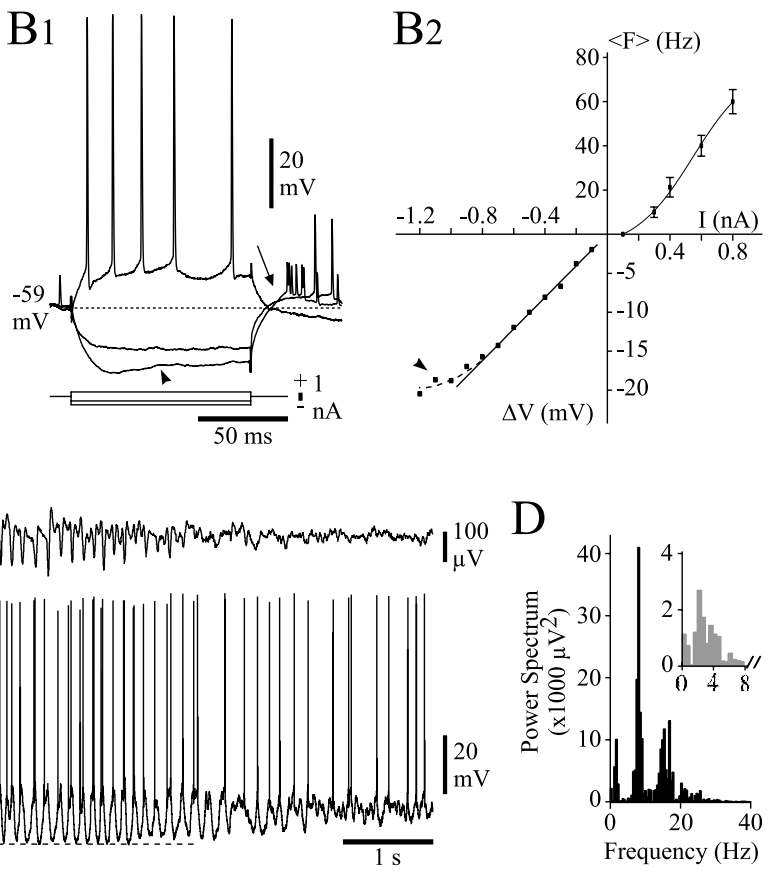

Figure 1. Intracellularly recorded activity of corticosubthalamic neurons during SWDs. $\boldsymbol{A}$, CSth neurons were identified by their egative current pulses are an average of six successive trials. The dashed line indicates the membrane potential from which the current steps were applied $(-59 \mathrm{mV})$. Note the sag in membrane voltage (arrowhead) during the $-1.1 \mathrm{nA}$-induced hyperpolarpartion of current intensity. The Spontaneous intracellular activity of a (Sth neuron (bottom trace) simultaneously recorded with the EEG (top trace). The occurmembrane potential are indicated on the left. In this and all following figures, the top trace in each pair is the EEG, and the bottom trace is the simultaneously recorded extracellular or intracellular voltage (unless stated otherwise). Error bars represent SEM.

induced a depolarizing "sag" of membrane potential (Fig. 1 B1, arrowhead), likely caused by a hyperpolarization-activated inward cationic current $\left(I_{\mathrm{h}}\right)$. The negative current pulse was followed immediately by a postinhibitory rebound of depolarization (Fig. $1 \mathrm{B1}$, arrow), possibly caused by the slow kinetics of $I_{\mathrm{h}}$ and/or by a low voltage-activated calcium potential.

Five recordings from CSth neurons (of seven) permitted observations on spontaneous transitions between interictal and ictal activities. During SWDs, CSth neurons exhibited suprathreshold rhythmic depolarizations (Figs. 1C, 2B1), which were temporally correlated with spike-wave complexes (Fig. 2 B1,C). These repetitive membrane depolarizations were superimposed on a tonic hyperpolarization of $11.3 \pm 0.1 \mathrm{mV}$ in amplitude (range, 8.7$15.5 \mathrm{mV} ; n=103$ from five cells) that lasted for the entire SWD (Fig. 1C, dashed line). Spontaneous membrane potential fluctuations in CSth neurons followed a unimodal distribution during interictal periods (Fig. 2A2) and changed to a bimodal distribution, with sustained depolarized and hyperpolarized potentials, during ictal epochs (Fig. 2 B2). Between SWDs, the mean value of membrane potential was $-60 \pm 4.55$ ( $\mathrm{SD}$, from -64 to -59.2 $\mathrm{mV} ; n=5$ cells) (Fig. 2A2). During cortical paroxysms, the av- 
A1

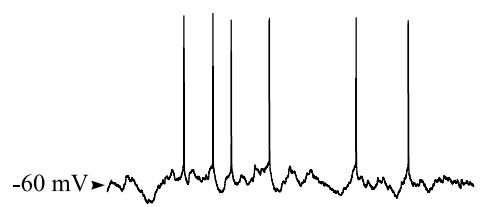

$\mathrm{B} 1$

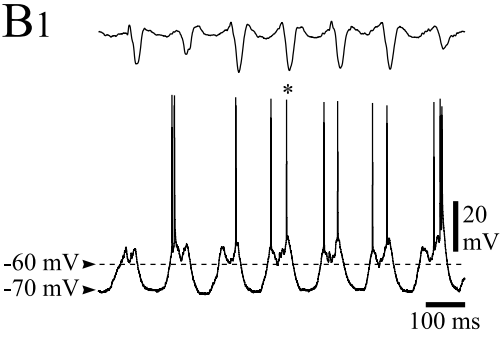

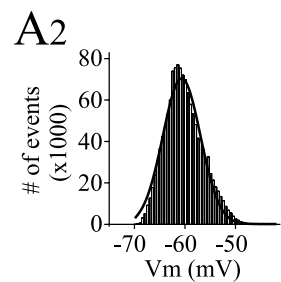

$\mathrm{C} 1$

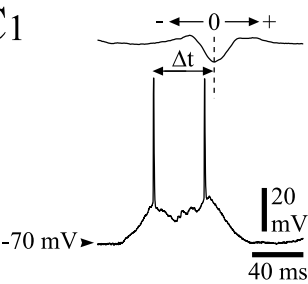

$\mathrm{B} 2$

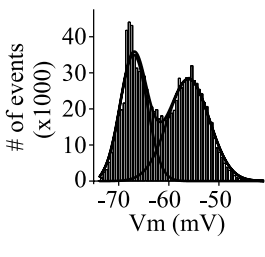

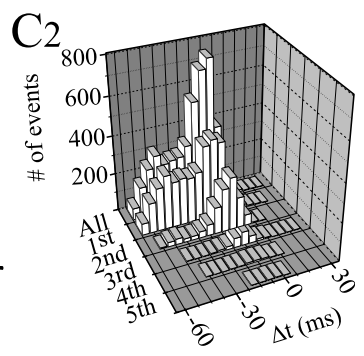

Figure 2. Membrane potential and firing properties of CSth neurons and their relationship to EEG activity. $\boldsymbol{A}$, Interictal activity. A1, Intracellular activity of a (Sth neuron (bottom trace) during the interictal period showing an irregular firing associated with a desynchronized EEG. A2, The corresponding membrane potential was unimodally distributed around a mean value of $-60 \mathrm{mV}$ $\left(n=1.3 \times 10^{6}\right.$ values; bin size, $0.5 \mathrm{mV} ; n=5$ cells; Gaussian fit, $\left.r^{2}=0.99\right) . \boldsymbol{B}, \boldsymbol{C}$, Ictal activity. $\boldsymbol{B} 1$, During SWD, the firing of CSth neurons was converted into a bursting mode with rhythmic membrane depolarizations associated with a hyperpolarized membrane potential (dashed line indicates the mean interictal membrane potential). The EEG and intracellular activity indicated by the asterisk is expanded in C1. The membrane potential of CSth neurons during cortical paroxysms was bimodally distributed with peak values at -68 and $-56 \mathrm{mV}\left(n=1.1 \times 10^{6}\right.$ values; bin size, $0.5 \mathrm{mV} ; n=5$ cells; double Gaussian fit, $\left.r^{2}=0.98\right)$. C, Temporal properties of CSth neuron firing during SWDs. C1, The timing of action potentials generated by CSth neurons $(\Delta t)$ was measured with respect to the peak of the corresponding EEG spike. C2, Histograms of CSth action potential arrival times $(\Delta t)$ distribution (bin size, $5 \mathrm{~ms}$ ). Latencies were separately calculated for the first ( $n=3171$ from 5 cells), second ( $n=1055$ from 5 cells), third ( $n=$ 212 from 5 cells), fourth ( $n=34$ from 4 cells), fifth ( $n=8$ from 3 cells), and sixth ( $n=2$ from 2 cells) action potentials occurring on the rhythmic depolarizations. The pooled data using all action potentials (All) ( $n=4482$ from 5 cells) were distributed bimodally. Records from $\boldsymbol{A} \mathbf{1}, \boldsymbol{B} \mathbf{1}$, and $\mathbf{C} \mathbf{1}$ are from the same cell-EEG pair.
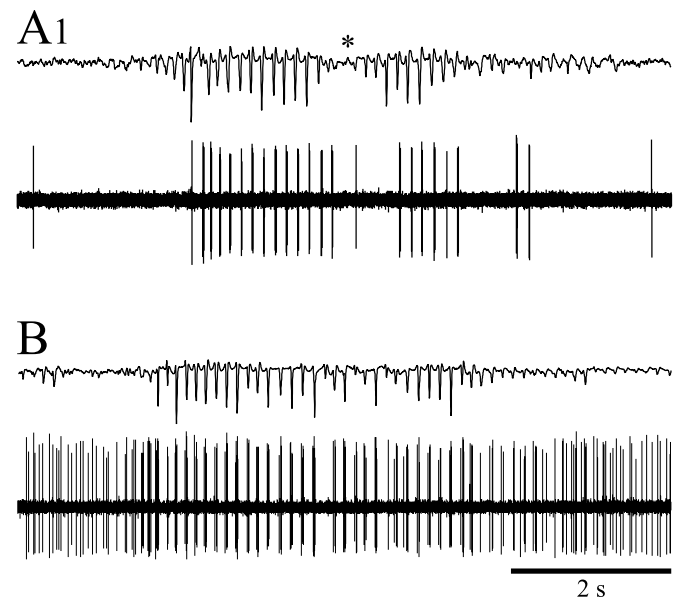

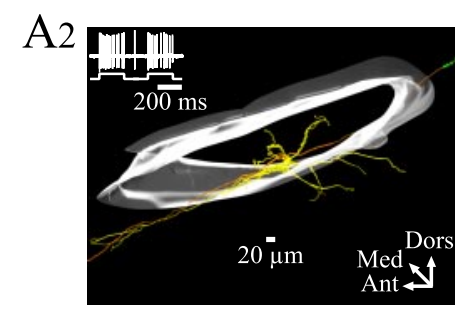

$\mathrm{C}$

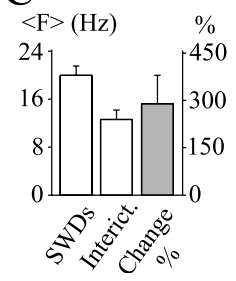

D

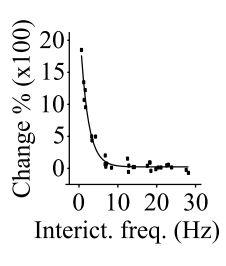

Figure 3. Extracellularly recorded activity of STN neurons during SWDs. A1, The very occasional single-spike firing of an STN neuron (bottom trace) was transformed into a high-frequency burst pattern during SWD in the EEG (top trace). A momentary interruption of the SWD (asterisk) was concomitant with an attenuation of the burst discharge. $\mathbf{A 2}$, Three-dimensional reconstruction of the STN neuron shown in $\boldsymbol{A 1}$, which was juxtacellularly injected with neurobiotin. The cell body was located in the region of the STN receiving inputs from the orofacial motor cortex from which the EEG was recorded. Note the numerous dendritic ramifications (in yellow) and the axon (in orange) that divides, close to the cell body, in anterior (Ant) and posterior collaterals directed to the pallidum and substantia nigra, respectively. The boundary of the STN is represented in light gray. $\boldsymbol{B}$, The background firing of another STN unit was a mixture of single spikes and short bursts. It was transformed into high-frequency bursts during the cortical seizure (top trace). $\boldsymbol{C}$, The mean firing frequency $(<F>)$ of STN neurons $(n=30)$ was significantly $(p<0.001)$ increased during SWDs $(n=292)$ compared with the interictal (Interict.) periods. The frequency increased by $289.5 \pm 90.1 \%(n=30$ cells) between interictal and ictal periods. $\boldsymbol{D}$, The percentage of firing frequency (freq.) increase decayed exponentially $\left(r^{2}=0.98\right)$ as a function of the interictal firing rate. Time calibration in $\boldsymbol{B}$ also applies to $\boldsymbol{A}$ 1. Ant, Anterior; Dors, dorsal; Med, medial. Error bars represent SEM. erage potential value reached during the rhythmic depolarizations and hyperpolarizations was $-55.7 \pm 1.4 \mathrm{mV}$ (SD, from -58 to $-54.4 \mathrm{mV} ; n=5$ cells) and $-67.9 \pm 2.6 \mathrm{mV}$ (SD, from -71 to -64.8 $\mathrm{mV} ; n=5$ cells), respectively (Fig. 2B2). The low occurrence of intermediate potentials demonstrates the rapid transitions made between the two preferred levels of membrane polarization (Fig. 2B1,B2). The appearance of ictal activity was also associated with a marked change in the firing pattern of CSth neurons, from an irregular activity to a rhythmic bursting mode (Figs. 1C, 2, compare A1, B1). Moreover, the mean spontaneous firing rate in CSth neurons increased by $92 \%$ during the SWDs compared with the interictal periods (interictal, $5 \pm 1.2 \mathrm{~Hz}$ vs SWDs, $9.2 \pm 0.3 \mathrm{~Hz} ; n=5$ cells; $p<$ $0.005)$, corresponding to a probability of firing in association with the EEG spike of 0.76 (from 0.66 to $0.91 ; n=4311$ EEG spikes from 227 SWDs; $n=5$ cells).

To assess the temporal relationship between the firing of CSth neurons and the surface cortical paroxysms, we measured the timing of individual action potentials in CSth neurons relative to the peak negativity of the corresponding spike component in the EEG (Fig. 2C1). The latencies of the first action potential were distributed bimodally with two preferential values close to -40 and $-12 \mathrm{~ms}(n=3171$ action potentials from five cells) (Fig. 2C2). A similar analysis using all action potentials (from one to six action potentials per depolarization cycle) also led to a bimodal distribution with two principal values at -38 and $-10 \mathrm{~ms}(n=4482 \mathrm{ac}-$ tion potentials from five cells) (Fig. 2C2).

\section{Extracellular recordings of STN neurons}

Changes in the electrical activity of STN neurons during SWDs were first examined by extracellular recordings $(n=30$ cells from six GAERS animals). Recorded cells were morphologically identified by juxtacellular injection of neurobiotin (see Materials and Methods) (Fig. 3A2). Labeled cells were located in the subthalamic projection field of the orofacial motor cortex (Kolomiets et al., 2001) and exhibited morphological characteristics of STN neurons, with a soma of diameter $\sim 20$ $\mu \mathrm{m}$, four to five primary dendrites, and axonal projections to the GP and the $\mathrm{SNr}$ (Beurrier et al., 1999; Bevan and Wilson, 1999) (Fig. 3A2) (see also Fig. 6A).

Extracellularly recorded STN neurons showed various patterns of background firing (Fig. $3 A 1, B$ ), characterized by either 
A

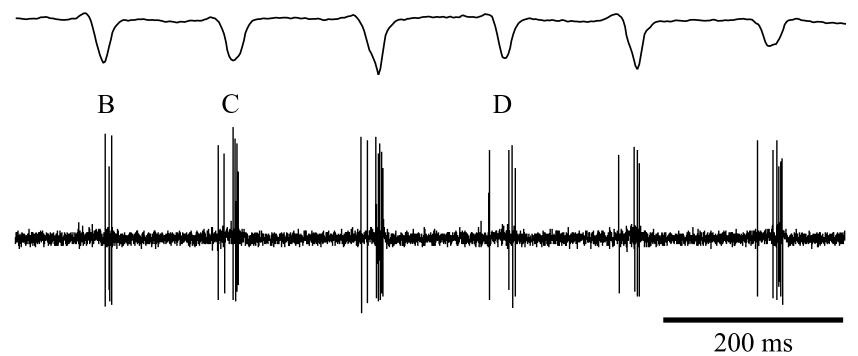

B
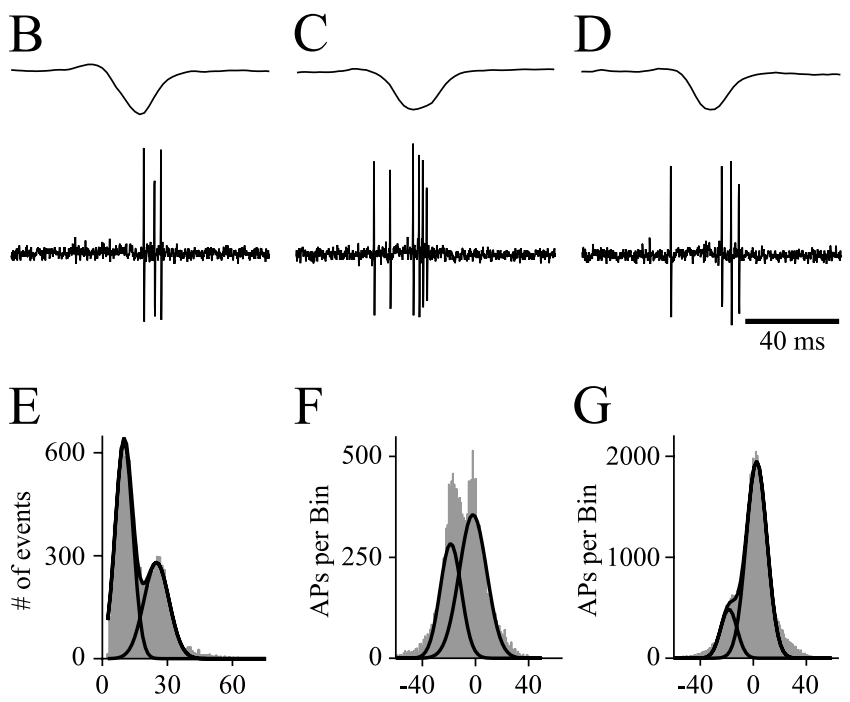

Burst duration (ms)
F

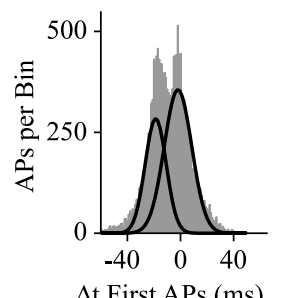

G

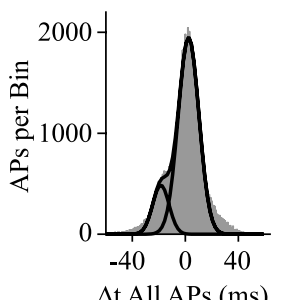

Figure 4. Properties of extracellularly recorded STN bursts during SWDS. $\boldsymbol{A}$, The recurrent bursts of action potentials (bottom trace) were correlated with EEG spikes. $\boldsymbol{B}-\boldsymbol{D}$, Expansion of records as indicated by the letters in $\boldsymbol{A}$. $\boldsymbol{E}$, STN burst duration was bimodally distributed (double Gaussian fit, $r^{2}=0.99$; bin size, $1 \mathrm{~ms} ; n=10,510$ bursts from 30 cells). $\boldsymbol{F}, \mathbf{G}$, Pooled histograms ( $n=30$ neurons) showing the distribution of latencies $(\Delta t)$ of the first $(\boldsymbol{F})$ and all $(\boldsymbol{G})$ of the action potentials in a burst with respect to the peak negativity of the EEG spike (same method of measurement as indicated in Fig. 2(1). In both histograms, the distribution was best fitted by a double Gaussian fit (first action potential, bin size, $1 \mathrm{~ms} ; r^{2}=0.96$; all action potentials, bin size, $\left.1 \mathrm{~ms} ; r^{2}=0.98\right)$. AP, Action potential.

low-frequency single action potentials (Fig. $3 A 1$ ) or a sustained irregular firing (Fig. 3B). Pooling all cells, the mean firing rate during interictal periods was $12.6 \pm 1.6 \mathrm{~Hz}$ (from 0.3 to $34.4 \mathrm{~Hz}$; $n=30$ cells) (Fig. $3 C$ ). During SWDs, the firing frequency of STN neurons reached a mean value of $21.8 \pm 0.6 \mathrm{~Hz}$ (range, $3-48 \mathrm{~Hz}$; from 292 SWDs; $n=30$ cells) (Fig. $3 C$ ), corresponding to a probability of discharge in association with individual EEG spikes of $0.88 \pm 0.02$ (from 0.68 to $1 ; n=30$ cells). We further characterized the SWDs-induced changes in the STN firing rate by measuring, for each cell, the increase in firing frequency as a function of its interictal value. A clear inverse relationship was found with the percentage increase decaying exponentially as the function of the mean interictal firing frequency (Fig. 3D). The paroxysmal activity resulted in a profound change in the firing pattern of STN neurons characterized by the occurrence of high-frequency bursts of action potentials, synchronous with the spike component of the EEG (Figs. $3 A 1, B, 4 A-D, 5 A, B 3$ ). STN bursts, which included $2-14$ action potentials $(4.11 \pm 0.02$ action potentials; $n=10,510$ bursts from 441 SWDs; $n=30$ cells), often consisted of one or two action potentials followed by a short electrical silence and a high-frequency cluster of spikes (Fig. 4C,D). The burst duration was bimodally distributed around 10 and $25 \mathrm{~ms}$

A

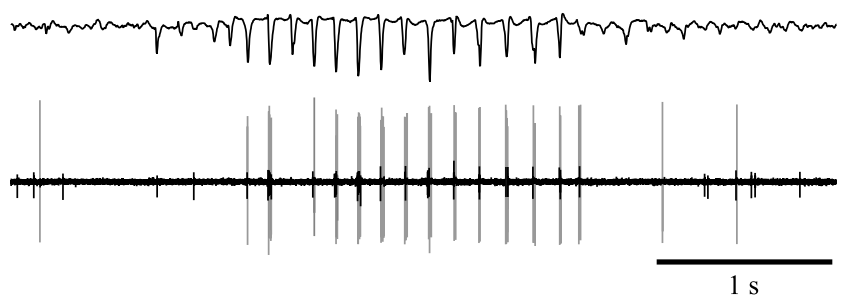

B1

B3
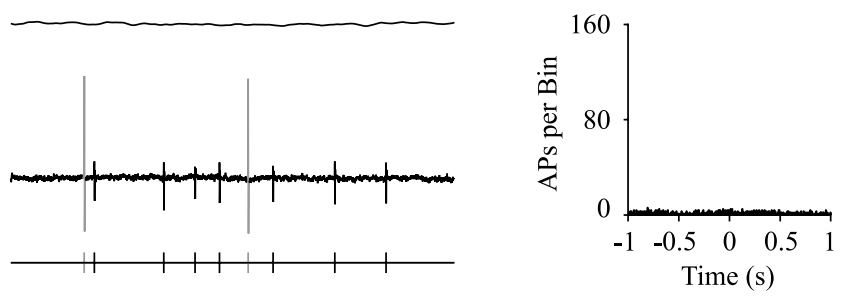

B2

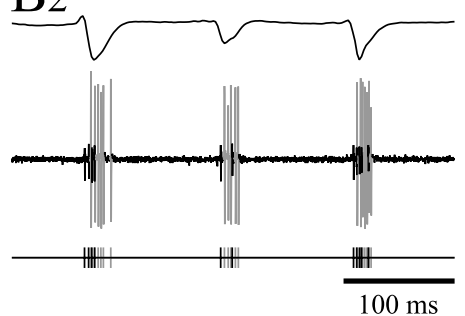

B4

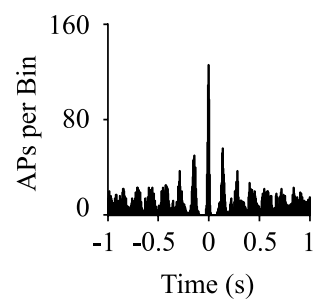

Figure 5. Synchronized bursting in the STN during SWDs. $\boldsymbol{A}$, Simultaneous recording of two STN units (black and gray action potentials) with the cortical EEG. B1, B2, The randomly occurring action potentials in two neighboring cells during interictal activity $(\boldsymbol{B} 1)$ became highly synchronized bursts, tightly correlated with the EEG spike during SWDs (B2). B3, B4, The synchronization of the two units by the SWD is clearly shown by the cross-correlation plots before (B3) and during (B4) the paroxysm (bin size, $5 \mathrm{~ms}$; 10 s sample). C, Histogram and Gaussian distribution (black line) showing the relative timing $(\Delta t)$ of the first action potentials of concomitantly occurring bursts (see inset) in the two units ( $n=2234$ bursts from 5 double units; bin size, $2 \mathrm{~ms}$ ). The bottom traces in $\boldsymbol{B} \mathbf{1}$ and $\boldsymbol{B} \mathbf{2}$, which represent the action potentials from the two units with the corresponding color code, show more clearly the individual patterns of spike firing. Time calibration in $\boldsymbol{B} \mathbf{2}$ also applies to $\boldsymbol{B}$. Results shown in $\boldsymbol{A}, \boldsymbol{B} \mathbf{1}$, and $\boldsymbol{B} \mathbf{2}$ are from the same double-unit recording. AP, Action potential.

(Fig. $4 E$ ), with a mean value of $16.8 \pm 0.1 \mathrm{~ms}$ (range, $2.1-75.6 \mathrm{~ms}$; $n=10,510$ bursts from 441 SWDs; $n=30$ cells) (Fig. $4 E$ ). The firing frequency during STN bursts was $206.8 \pm 0.9 \mathrm{~Hz}$ (range, $58-670 \mathrm{~Hz} ; n=10,510$ bursts from 441 SWDs; $n=30$ cells).

As observed in CSth neurons, the latency of the first action potential in the STN burst was distributed bimodally (Fig. 4F) with respect to the peak negativity of the corresponding EEG spike, with two principal values at -18.7 and $-1.9 \mathrm{~ms}(n=15643$ action potentials from 441 SWDs; $n=30$ cells). A similar analysis of all the action potentials in a burst also led to a bimodal distri- 

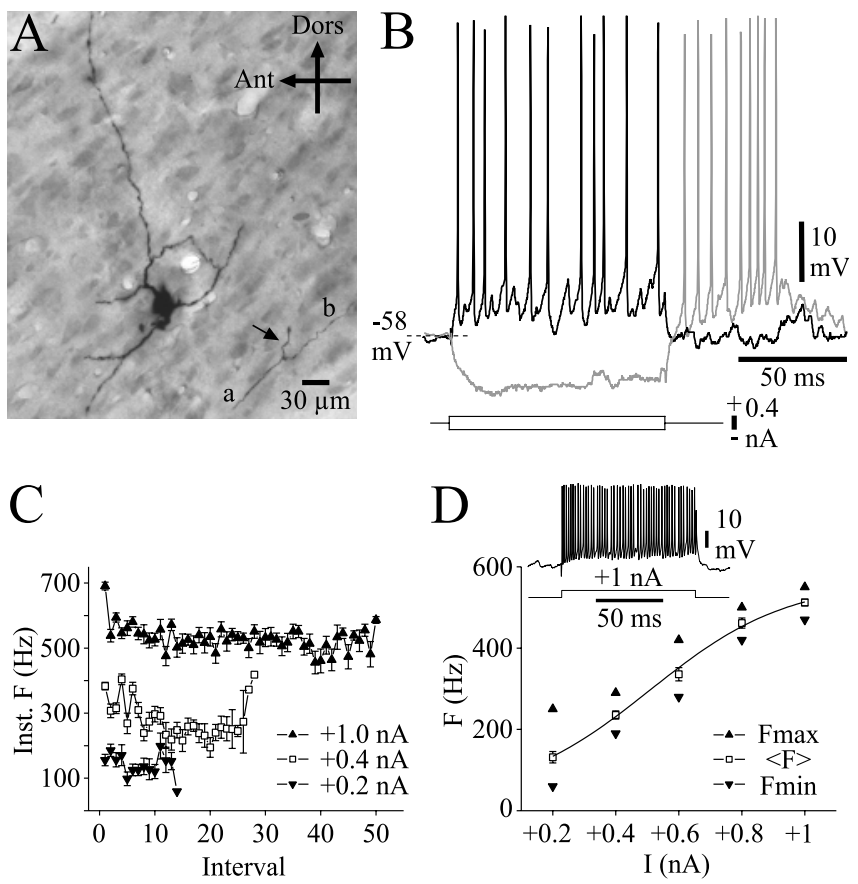

Figure 6. Morphological and electrophysiological properties of intracellularly recorded STN neurons. $A$, Microphotograph of an STN neuron intracellularly injected with neurobiotin. This cell exhibited characteristic morphological features, including an axon (arrow) that divides into anterior (a) and posterior (b) collaterals. $\boldsymbol{B}$ - $\boldsymbol{D}$, Electrical membrane properties of GAERS STN neurons. $\boldsymbol{B}$, Voltage responses (top traces) of the cell shown in $\boldsymbol{A}$ to intracellular injections of square current pulses (bottom traces) from rest $(-58 \mathrm{mV}$ ). After the termination of the hyperpolarizing current step, an excitatory rebound initiated a burst of action potentials (gray trace). C, Plot of the instantaneous (Inst.) firing frequency in response to positive current step pulses of increasing intensities. From the point of maximal firing frequency $(+1 \mathrm{nA})$, a moderate frequency adaptation developed slowly. $\boldsymbol{D}$, Mean firing frequency $(<F\rangle)$ as a sigmoidal function $\left(r^{2}=0.997\right)$ of the intensity of square current pulses. The inset shows sustained high-frequency $(\sim 500 \mathrm{~Hz})$ firing induced by a $+1 \mathrm{nA}$ pulse. Results shown in $\boldsymbol{A}-\boldsymbol{D}$ are from the same cell. Ant, Anterior; Dors, dorsal. Error bars represent SEM.

bution with two peak values of -18.5 and $+2.5 \mathrm{~ms}(n=49,259$ action potentials from 441 SWDs; $n=30$ cells) (Fig. $4 G$ ).

Multiunit recordings $(n=5)$ revealed similar firing properties, both during and outside periods of SWDs (Fig. 5A). These recordings also highlighted how the unrelated firing patterns of two neighboring STN cells in the absence of seizures (Fig. $5 B 1, B 3)$ became highly correlated with each other and tightly time-locked to the EEG spike during SWDs (Fig. 5B2,B4). These recordings also showed that the first action potential in a burst from one STN neuron could either precede or follow the first action potential in the concomitant burst of the neighboring cell, with a mean delay between these two action potentials of $2.3 \pm$ 0.2 (from 0.3 to $37.9 \mathrm{~ms} ; n=2234$ action potentials from 86 SWDs; five double unit recordings from two GAERS) (Fig. 5C).

\section{Intracellular recordings of STN neurons: electrical membrane properties}

Intracellular recordings were made from STN neurons $(n=9$ cells from nine GAERS) to explore the membrane and synaptic mechanisms responsible for the generation of STN bursts during SWDs. The passive membrane properties of STN neurons included an interictal membrane potential of $-59.3 \pm 0.4 \mathrm{mV}(n=$ $9)$, an apparent input resistance of $23.8 \pm 3.1 \mathrm{M} \Omega(n=6)$, and a membrane time constant of $5.31 \pm 0.97 \mathrm{~ms}(n=6)$ (Fig. $6 B)$. Action potentials of intracellularly recorded STN neurons had an amplitude and duration of $47.5 \pm 1.9 \mathrm{mV}$ and $0.75 \pm 0.07 \mathrm{~ms}$
( $n=9$ cells), respectively, with a voltage threshold of $-50.8 \pm 0.5$ $\mathrm{mV}$ ( $n=9$ cells). The $V-I$ relationship, obtained from negative current pulses of amplitude -0.2 to $-0.8 \mathrm{nA}$, was linear, indicating the absence of membrane rectification in the hyperpolarizing direction (data not shown). The location and the morphological features of these neurons (Fig. 6A) were similar to those described after juxtacellular dye injection (see Fig. 3A2), including a soma of $25 \mu \mathrm{m}$ in diameter, four primary dendrites, and a bifurcated axon projecting to both SNr and GP, indicating the identity of extracellularly and intracellularly recorded STN neurons.

Although their spontaneous interictal firing was slow $(<35$ $\mathrm{Hz}$ ), STN neurons were capable of firing at rates as high as several hundred Hertz during SWD-associated spontaneous bursting (see above) or in response to depolarizing current pulses (Fig. $6 B, D)$. The current-driven discharge of STN neurons was characterized by a slight spike frequency adaptation and showed a very wide dynamic range, with peak firing rates as high as $500 \mathrm{~Hz}$ (Fig. 6C,D). Despite the passage of large depolarizing currents, the membrane potential between action potentials traversed approximately the same voltage range seen during spontaneous firing. Interestingly, high-frequency bursts similar to those discharged during SWDs (Figs. 4A-D) occurred as rebound responses after hyperpolarizing current pulses (Fig. 6B, gray trace).

These membrane properties of the GAERS STN neurons closely resemble those previously described in vitro from nonepileptic rats (Bevan and Wilson, 1999; Beurrier et al., 1999; Bevan et al., 2000; Hallworth et al., 2003). Thus, it is very unlikely that the epileptiform discharges of STN neurons during absence seizures were caused by a specific alteration in their intrinsic excitability (see Discussion).

\section{Intracellular recordings of STN neurons: cellular events associated with SWDs}

In five intracellularly recorded STN neurons, spontaneous transitions between interictal and ictal periods were characterized by a switch from single-spike activity to burst firing mode similar to that observed in extracellular records. The rhythmic bursting of STN neurons during SWDs was accompanied by a triphasic sequence of intracellular events (Fig. 7B): (1) an early shortduration depolarizing potential that could generate an action potential, (2) a transient, large membrane hyperpolarization that lasted $16.6 \pm 0.1 \mathrm{~ms}$ (from 4.2 to $30.5 \mathrm{~ms} ; n=1801$ from five cells), and (3) a postinhibitory rebound of depolarization leading to a burst with a relatively fixed latencies for the first three action potentials. The rhythmic hyperpolarizations were increased in amplitude under DC depolarization (Fig. 7C1) and reversed in polarity for membrane potentials less than $-73 \mathrm{mV}$ (Fig. 7C3). These observations strongly suggest that the rhythmic hyperpolarizations in STN neurons during SWDs represent $\mathrm{Cl}^{-}$dependant, $\mathrm{GABA}_{\mathrm{A}}$-mediated, hyperpolarizing postsynaptic potentials (IPSPs) (see Discussion). These presumed IPSPs started $10.36 \pm 0.13 \mathrm{~ms}$ (range, -40 to $+6.17 \mathrm{~ms} ; n=1801$ IPSPs from five cells) before the spike component of SWDs and reached their peak potential at $-2.73 \pm 0.13 \mathrm{~ms}$ (range, -30 to $+14 \mathrm{~ms} ; n=$ 1801 IPSPs from five cells) (Figs. 7B, 9B).

\section{Extracellular recordings of GP neurons}

We made extracellular recordings of GP neurons ( $n=13$ from five GAERS) to examine whether these neurons were involved in the rhythmic bursting of the STN during SWDs. We found two distinct GP cell populations, in term of firing pattern, without any evidence for a differential topographical distribution within 
the nucleus. The smaller group of GP neurons [called "early discharging" GP (EDGP) neurons; $n=3$ of 13 cells] was characterized by a slow irregular background firing that shifted, during SWDs, to rhythmic single spikes or short bursts (two to four action potentials) correlated with the EEG spike (Fig. 8A1,A2). This rhythmic firing was maintained throughout the cortical seizure. The mean latency of all action potentials to the peak negativity of the EEG spike was $-18.67 \pm 0.14 \mathrm{~ms}(n=$ 2409 action potentials from three cells) (Fig. 8 A2). Simultaneous recordings ( $n=$ 2 from two GAERS) of ED-GP neurons with STN neurons showed that their random firing patterns in the absence of SWDs (Fig. 8C1,C2) became highly correlated with each other (Fig. 8D2) and tightly time-locked to the spike-wave complexes (Fig. 8D1) during seizures.

In contrast, the main class of GP neurons, called "pausing" GP (P-GP) neurons ( $n=10$ of 13 cells), displayed a tonic interictal activity. During SWDs, discharges were transformed into a burst firing pattern with interburst periods that coincided with cortical EEG spikes (Fig. $8 B 1, B 2)$. These periods of electrical silence in P-GP neurons occurred $14.76 \pm$ $0.21 \mathrm{~ms}$ before the EEG spike $(n=1260$ "pauses" from 10 cells) (Fig. 8B2) and lasted for $32.1 \pm 11.5 \mathrm{~ms}$ (SD, range, $15.7-$ $49.2 \mathrm{~ms} ; n=1260$ pauses from 10 cells). The recovery after the electrical silence was systematically associated with a transient increase in the firing rate (Figs. $8 B 2$, inset, $9 A$, bottom trace).

\section{Discussion}

The present study provides the first description of electrical activities in the cortico-subthalamo-pallidal networks during absence seizures. Our principal findings are: (1) during SWDs, CSth neurons exhibit rhythmic suprathreshold depolarizations superimposed on a sustained hyperpolarization lasting for the entire cortical paroxysm, (2) STN neurons display synchronized repetitive bursts of action potentials in-phase with EEG spikes, (3) intracellular analysis indicates that rhythmic firing in STN neurons results from an early excitation, followed by an hyperpolarization and then a late excitation, and (4) during SWDs, GP neurons display either a rhythmic bursting synchronous with the cortical paroxysm or a sustained firing momentarily interrupted by EEG spikes. These results indicate that the propagation of cortical paroxysms through the cortico-subthalamo-pallidal pathway generates a bursting pattern in the STN that might produce a powerful phasic synaptic excitation of the basal ganglia output nuclei.

\section{Rhythmic bursting of CSth neurons during SWDs}

To our knowledge, the present experiments provide the first description of the intracellular activity of identified CSth neurons. The occurrence of SWDs in the EEG was concomitant with a sudden, pronounced modification in the activity of CSth neu- rons. The interictal, small-amplitude, irregular synaptic activity in CSth neurons, generating an erratic firing pattern, changed, during an SWD, into a step-like behavior with suprathreshold depolarizations in-phase with the EEG spikes. As previously observed in other GAERS cortical neurons (Charpier et al., 1999; Slaght et al., 2002a,b), the SWD-associated rhythmic depolarizations in CSth neurons were concomitant with a tonic membrane hyperpolarization, likely attributable to a synaptic disfacilitation responsible for an increase in membrane resistance (Contreras et al., 1996; Charpier et al., 1999; Slaght et al., 2002b).

Interestingly, the synaptic activity as well as the firing rate of CSth neurons during SWDs differ significantly from those of GAERS corticostriatal neurons (Slaght et al., 2002b, 2004), which exhibit oscillating membrane depolarizations that remain subthreshold or elicit single action potentials during seizures. The increased excitability of CSth neurons could result from interactions between synaptic inputs and specific voltage-gated intrinsic channels. Consistent with this hypothesis, we observed in CSth neurons, in response to hyperpolarizing current injection, a depolarizing sag of membrane potential followed by a postanodal rebound of excitation. These observations provide indirect evidence that CSth neurons may express $I_{\mathrm{h}}$ and a low-voltage activated calcium current (Fig. 1B1), which act together to promote oscillations and repetitive firing in cortical neurons (for review, see Reyes, 2001; Migliore and Shepherd, 2002). 
A 1

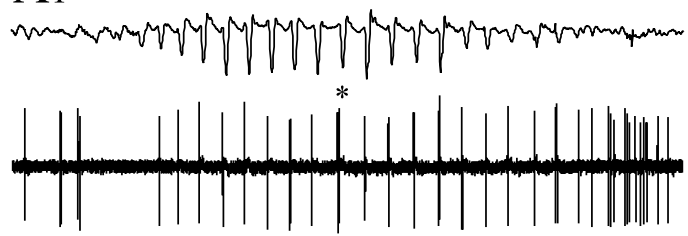

B1

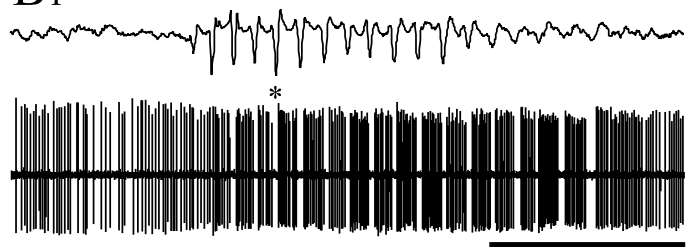

$1 \mathrm{~s}$

$\mathrm{C} 1$

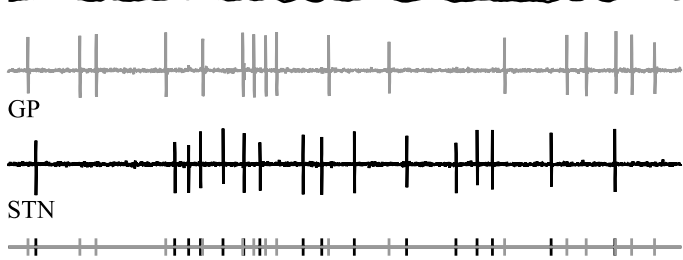

D1

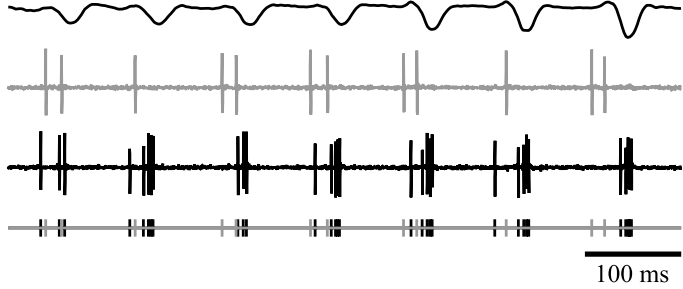

A2

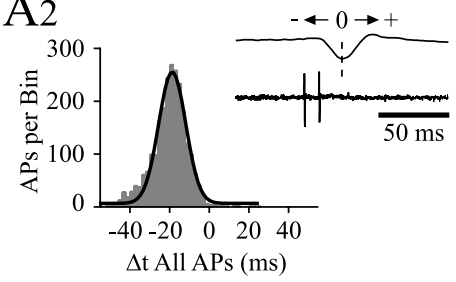

$\mathrm{B} 2$

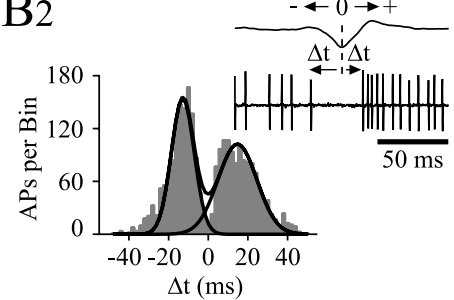

$\mathrm{C}_{2}$

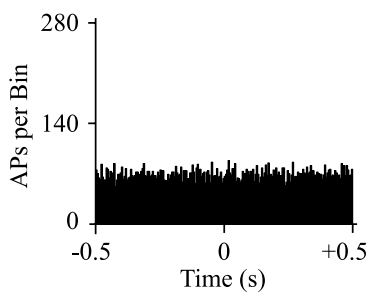

D2

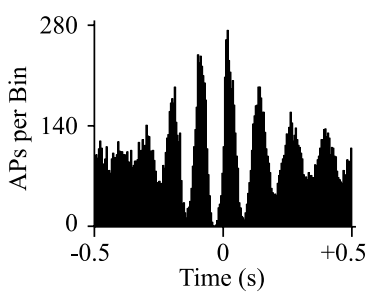

Figure 8. Extracellular recordings from GP neurons during SWDS. $\boldsymbol{A}, \mathrm{ED}-\mathrm{GP}$ neuron. $\boldsymbol{A}$ 1, The irregular firing pattern of this ED-GP neuron during the interictal period was converted into rhythmic bursting by the SWD. A2, Distribution of the timing of all action potentials ( $n=2409$ action potentials from 3 cells; bin size, $2 \mathrm{~ms}$ ) relative to the EEG spike (inset, expanded record from $\boldsymbol{A} 1$ as indicated by the asterisk). The distribution, which was best fitted by a Gaussian curve $\left(r^{2}=0.98\right)$, indicated that ED-GP neurons usually discharged before the EEG spike. $\boldsymbol{B}, \mathrm{P}$-GP neurons. $\boldsymbol{B}$ 1, The sustained background firing of this unit was transformed during a seizure into a pattern of bursts separated by cessation of firing concomitant with the EEG spike (inset in $\boldsymbol{B} 2$ taken from $\boldsymbol{B} \mathbf{1}$ as indicated by the asterisk). B2, The temporal relationship between the pause in firing and the EEG spike was quantified by measuring the timing $(\Delta t)$ of the start and the end of the pause with respect to the EEG spike (inset). The corresponding pooled data histogram from 10 P-GP cells was bimodally distributed around -12.9 and $14.7 \mathrm{~ms}$ ( $n=2520$ action potentials from 1260 pauses; bin size, $2 \mathrm{~ms}$; double Gaussian fit, $\left.r^{2}=0.9\right)$. C, D, Simultaneous extracellular recordings of an ED-GP (GP; gray) and of an STN (black) neuron during interictal (C1) and ictal (D1) periods. C2, D2, The synchronization of the two units by the SWD is clearly shown by the cross-correlation plots between ( $(2)$ and during $(\boldsymbol{D 2})$ seizures ( $n=31$ seizures; bin size, $5 \mathrm{~ms}$; 90 s sample). Results shown in $\boldsymbol{C}$ and $\boldsymbol{D}$ are from the same EEG-GP-STN triple recording. AP, Action potential.

\section{Origin of the rhythmic excitation and inhibition in STN neurons during SWDs}

The GAERS STN neurons, intracellularly recorded in the course of this study, displayed membrane properties including membrane potential, postanodal rebound of excitation, action potential properties, and $V-I$ and $F-I$ relationships similar to those previously described in vitro from normal rats (Beurrier et al., 1999, 2000; Bevan and Wilson, 1999; Bevan et al., 2000, 2002a). These important observations indicate that the increased firing rate in STN neurons accompanying the SWDs does not result from an altered intrinsic excitability.

The rhythmic bursts in STN neurons, observed in extracellular recordings during SWDs, were characterized frequently by an early action potential, usually preceding the corresponding EEG spike, followed by a short electrical silence $(<25 \mathrm{~ms})$ and then a high-frequency cluster of action potentials. This pattern of electrical events in the STN is very similar to that observed after electrical stimulation of the motor cortex (Kitai and Deniau, 1981; Kita, 1994; Kolomiets et al., 2001). Intracellular recordings let us characterize membrane and synaptic events underlying this triphasic response. The initial discharge of STN neurons during cortical paroxysms was elicited by a short depolarizing potential likely induced by the early discharge of CSth neurons (Fig. 9), which provide powerful excitatory synaptic inputs to STN neurons (Kitai and Deniau, 1981; Kita, 1994; Magill et al., 2000; Kolomiets et al., 2001). The brief silence within the STN bursts associated with the spike-wave complexes resulted from a transient $(\sim 17 \mathrm{~ms})$ hyperpolarization that reversed in polarity at membrane potentials less than $-73 \mathrm{mV}$ (Fig. 7C3). This value is very close to the chloride equilibrium potential of $\mathrm{GABA}_{\mathrm{A}}$ current measured in STN neurons from normal rats (Bevan et al., 2000, 2002a). Thus, rhythmic hyperpolarizations observed during SWDs are probably $\mathrm{GABA}_{\mathrm{A}}$-mediated IPSPs that may be induced by a subpopulation of GABAergic pallidosubthalamic neurons $(\sim 25 \%$ of the GP neurons described in this study), which generate bursts of action potentials just before $(\sim 16 \mathrm{~ms})$ the peak of the STN inhibitory potentials (Fig. 9, ED-GP neurons). The burst activity in ED-GP neurons may well be initiated, at least in part, by a short-latency excitation attributable to the early firing of excitatory subthalamopallidal neurons (Kita and Kitai, 1991; Magill et al., 2000; Nambu et al., 2000) (Fig. 9). The postinhibitory rebound of firing in STN neurons may result from synergistic interactions between active membrane properties and excitatory synaptic inputs. Indeed, STN neurons possess low-threshold calcium channels responsible, at least in part, for the generation of burst activity after membrane hyperpolarization (Beurrier et al., 1999, 2000; Bevan and Wilson, 1999; Bevan et al., 2000; Song et al., 2000). Such intrinsic rebound properties in STN neurons, which were also found in the present study on removal of large-amplitude hyperpolarizing current pulses (Fig. 6B), might contribute to the postinhibitory (late) bursting in STN neurons (Fig. 9). Moreover, in accordance with previous in vitro studies (Bevan et al., 2002b), we found that the repetitive action potentials that followed large-amplitude IPSPs impinging on STN neurons were almost exactly in-phase (Fig. $7 B$ ), an intrinsic process that would tend to promote coherent bursting in the STN during absence seizures (Figs. 5B2, 4). The delayed firing of CSth neurons would provide an additional excitatory synaptic mechanism promoting the late STN bursting during SWDs (Fig. 9).

The functional impact of P-GP neurons on STN activity re- 


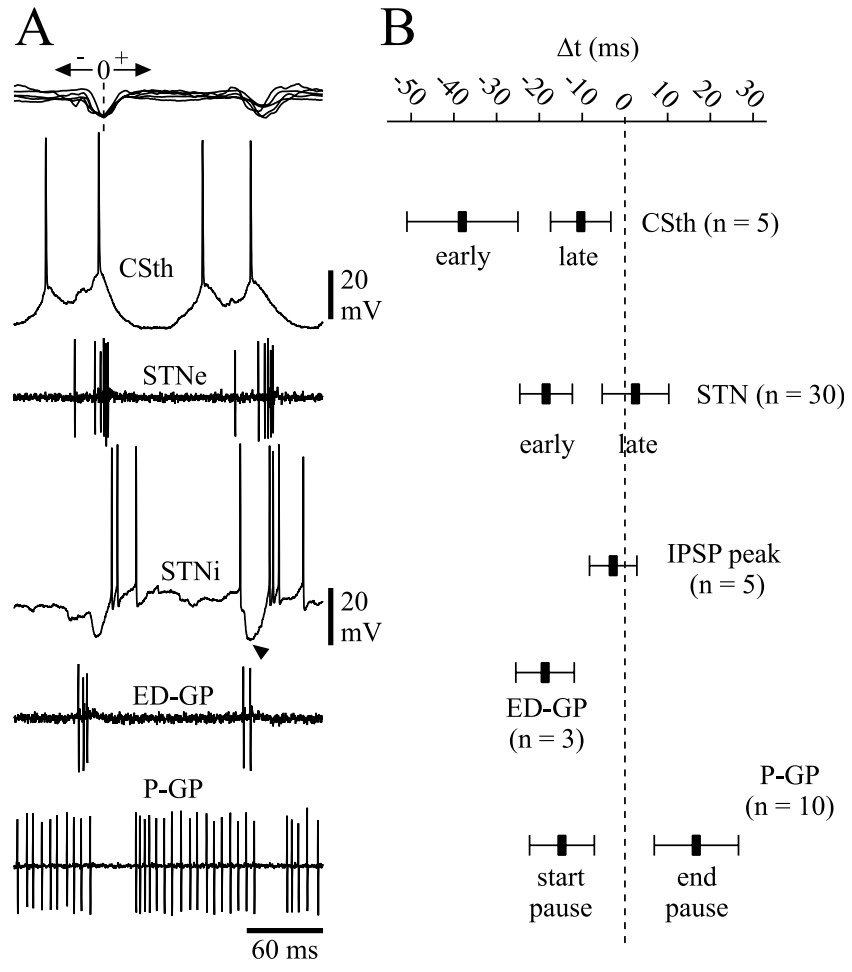

Figure 9. Temporal relationship between SWDs from the surface EEG and activity in neurons of the cortico-subthalamo-pallidal pathway. $\boldsymbol{A}$, Examples of two successive EEG spike-wave complexes (top traces) and the corresponding (1) intracellular activity of a CSth neuron, (2) extracellular firing of an STN neuron (STNe), (3) intracellular recording from an STN neuron (STNi), and extracellular discharges of (4) an ED-GP neuron and (5) a P-GP neuron. The peak of the STN IPSP is indicated by an arrowhead. $\boldsymbol{B}$, Averaged timing (mean \pm SD) of action potential generation with respect to the EEG spike (dashed line). When timing was bimodally distributed, with early and late discharges (as for CSth, STNe, see Figs. 2, 4), we considered the mean and the SD of double Gaussian fits. The number of computed neuron-EEG pairs is indicated.

mains unclear. However, we can propose that the transient interruption of P-GP neuron firing during EEG spikes, potentially caused by intra-GP inhibitory inputs (Kita and Kitai, 1994) from ED-GP neurons (Fig. 9), provides a permissive mechanism to reinforce the relative weight of the corticosubthalamic excitatory inputs. Moreover, the sustained desynchronized firing in P-GP neurons between EEG spikes could contribute to the interburst silence in the STN by increasing the STN neurons membrane conductance.

\section{Pathophysiology}

The main finding of the present study is the synchronized rhythmic bursting of STN neurons during absence seizures. This novel result, together with the lack of action potential firing in GAERS striatal projection neurons during ictal activity (Slaght et al., 2004), strongly suggests a change in the balance between excitation and inhibition in the basal ganglia output nuclei that leads to a sudden reinforcement of the synaptic excitation originating from the STN. This hypothesis is supported by recent findings from freely moving GAERS showing that SNr neurons exhibit a synchronized bursting concomitant with SWDs (Deransart and Depaulis, 2002; Deransart et al., 2003).

A potential implication of the STN in the control of absence seizures has recently emerged from pharmacological studies and deep brain stimulation in GAERS (Deransart et al., 1998; Vercueil et al., 1998), showing that neurotoxic lesions or high-frequency electrical stimulation of STN negatively modulate cortical parox- ysms. These data are consistent with the antiepileptic effects of intranigral injections of $\mathrm{GABA}_{\mathrm{A}}$ agonists or NMDA antagonists in the GAERS SNr (Depaulis et al., 1988, 1989; Deransart et al., $1996,1998,2001)$ and the aggravation of absence seizures induced by application of $\mathrm{GABA}_{\mathrm{A}}$ antagonist in the $\mathrm{SNr}$ (Deransart et al., 1998). Changes in the output of STN neurons associated with cortical SWDs could, therefore, provide a subcortical mechanism participating in the control of the abnormal oscillations in the thalamocortical loop. First, the synchronized bursting of subthalamonigral neurons during SWDs, associated with the electrical silence in GABAergic striatonigral cells (Slaght et al., 2004), might prolong seizures via a repetitive excitation of $\mathrm{SNr}$ neurons (Deransart and Depaulis, 2002; Deransart et al., 2003). Such a positive modulation of SWDs could result from the repetitive inhibition of thalamocortical neurons by $\mathrm{SNr}$ (Di Chiara et al., 1979; Deniau and Chevalier, 1985). Indeed, if the nigral-induced thalamic rhythmicity is in-phase with SWDs, it could, by a resonance phenomenon, maintain the paroxysmal thalamocortical oscillations. Second, the recovery of the irregular, desynchronized, firing in STN neurons at the end of the SWD, together with the rebound of excitation in striatal projection neurons (Slaght et al., 2004), could initiate the postictal decrease in the activity of nigrothalamic neurons (Deransart et al., 2003) and so participate in the termination of the seizure.

\section{References}

Afsharpour S (1985) Topographical projections of the cerebral cortex to the subthalamic nucleus. J Comp Neurol 236:14-28.

Beurrier C, Congar P, Bioulac B, Hammond C (1999) Subthalamic nucleus neurons switch from single-spike activity to burst-firing mode. J Neurosci 19:599-609.

Beurrier C, Bioulac B, Hammond C (2000) Slowly inactivating sodium current $(\mathrm{I}(\mathrm{NaP}))$ underlies single-spike activity in rat subthalamic neurons. J Neurophysiol 83:1951-1957.

Bevan MD, Wilson CJ (1999) Mechanisms underlying spontaneous oscillation and rhythmic firing in rat subthalamic neurons. J Neurosci 19:7617-7628.

Bevan MD, Wilson CJ, Bolam JP, Magill PJ (2000) Equilibrium potential of $\mathrm{GABA}(\mathrm{A})$ current and implications for rebound burst firing in rat subthalamic neurons in vitro. J Neurophysiol 83:3169-3172.

Bevan MD, Magill PJ, Hallworth NE, Bolam JP, Wilson CJ (2002a) Regulation of the timing and pattern of action potential generation in rat subthalamic neurons in vitro by GABA-A IPSPs. J Neurophysiol 87:1348-1362.

Bevan MD, Magill PJ, Terman D, Bolam JP, Wilson CJ (2002b) Move to the rhythm: oscillations in the subthalamic nucleus-external globus pallidus network. Trends Neurosci 25:525-531.

Bruno RM, Khatri V, Land PW, Simons DJ (2003) Thalamocortical angular tuning domains within individual barrels of rat somatosensory cortex. J Neurosci 23:9565-9574.

Charpier S, Lereshe N, Deniau J-M, Mahon S, Hughes SW, Crunelli V (1999) On the putative contribution of $\mathrm{GABA}_{\mathrm{B}}$ receptors to the electrical events occurring during spontaneous spike and waves discharges. Neuropharmacology 38:1699-1706.

Connors BW, Gutnick MJ (1990) Intrinsic firing patterns of diverse neocortical neurons. Trends Neurosci 13:99-104.

Contreras D, Timofeev I, Steriade M (1996) Mechanisms of long-lasting hyperpolarizations underlying slow sleep oscillations in cat corticothalamic networks. J Physiol (Lond) 494:251-264.

Crunelli V, Leresche N (2002) Childhood absence epilepsy: genes, channels, neurons and networks. Nat Rev Neurosci 3:371-382.

Danober L, Deransart C, Depaulis A, Vergnes M, Marescaux C (1998) Pathophysiological mechanisms of genetic absence epilepsy in the rat. Prog Neurobiol 55:27-57.

Deniau JM, Chevalier G (1985) Disinhibition as a basic process in the expression of striatal functions. II. The striato-nigral influence on thalamocortical cells of the ventromedial thalamic nucleus. Brain Res 334:227-233.

Deniau JM, Hammond C, Chevalier G, Feger J (1978) Evidence for 
branched subthalamic nucleus projections to substantia nigra, entopeduncular nucleus and globus pallidus. Neurosci Lett 9:117-121.

Depaulis A, Vergnes M, Marescaux C, Lannes B, Warter J (1988) Evidence that activation of GABA receptors in the substantia nigra suppresses spontaneous spike-and-wave discharges in the rat. Brain Res 448:20-29.

Depaulis A, Snead OI, Marescaux C, Vergnes M (1989) Suppressive effects of intranigral injection of muscimol in three models of generalized nonconvulsive epilepsy induced by chemical agents. Brain Res 498:64-72.

Deransart C, Depaulis A (2002) The control of seizures by the basal ganglia? A review of experimental data. Epileptic Disord 4 [Suppl 3]:S61-S72.

Deransart C, Marescaux C, Depaulis A (1996) Involvement of nigral glutamatergic inputs in the control of seizures in a genetic model of absence epilepsy in the rat. Neuroscience 71:721-728.

Deransart C, Vercueil L, Marescaux C, Depaulis A (1998) The role of basal ganglia in the control of generalized absence seizures. Epilepsy Res 32:213-223.

Deransart C, Le-Pham BT, Hirsch E, Marescaux C, Depaulis A (2001) Inhibition of the substantia nigra suppresses absences and clonic seizures in audiogenic rats, but not tonic seizures: evidence for seizure specificity of the nigral control. Neuroscience 105:203-211.

Deransart C, Hellwig B, Heupel-Reuter M, Leger JF, Heck D, Lucking CH (2003) Single-unit analysis of substantia nigra pars reticulata neurons in freely behaving rats with genetic absence epilepsy. Epilepsia 44:1513-1520.

Di Chiara G, Porceddu ML, Morelli M, Mulas ML, Gessa GL (1979) Evidence for a GABAergic projection from the substantia nigra to the ventromedial thalamus and to the superior colliculus of the rat. Brain Res $176: 273-284$

Hall RD, Lindholm EP (1974) Organization of motor and somatosensory neocortex in the albino rat. Brain Res 66:23-28.

Hallworth NE, Wilson CJ, Bevan MD (2003) Apamin-sensitive small conductance calcium-activated potassium channels, through their selective coupling to voltage-gated calcium channels, are critical determinants of the precision, pace, and pattern of action potential generation in rat subthalamic nucleus neurons in vitro. J Neurosci 23:7525-7542.

Kita H (1994) Physiology of two disynaptic pathways from the sensorimotor cortex to the basal ganglia output nuclei. In: The basal ganglia IV (Percheron G, McKenzie JS, Féger J, eds), pp 263-276. New York: Plenum.

Kita H, Kitai ST (1991) Intracellular study of rat globus pallidus neurons: membrane properties and responses to neostriatal, subthalamic and nigral stimulation. Brain Res 564:296-305.

Kita H, Kitai ST (1994) The morphology of globus pallidus projection neurons in the rat: an intracellular staining study. Brain Res 636:308-319.

Kitai ST, Deniau JM (1981) Cortical inputs to the subthalamus: intracellular analysis. Brain Res 214:411-415.

Kolomiets BP, Deniau JM, Mailly P, Menetrey A, Glowinski J, Thierry AM (2001) Segregation and convergence of information flow through the cortico-subthalamic pathways. J Neurosci 21:5764-5772.

Magill PJ, Bolam JP, Bevan MD (2000) Relationship of activity in the subthalamic nucleus-globus pallidus network to cortical electroencephalogram. J Neurosci 20:820-833.

Magill PJ, Bolam JP, Bevan MD (2001) Dopamine regulates the impact of the cerebral cortex on the subthalamic nucleus-globus pallidus network. Neuroscience 106:313-330.

Mahon S, Casassus G, Mulle C, Charpier S (2003) Spike-dependent intrinsic plasticity increases firing probability in rat striatal neurons in vivo. J Physiol (Lond) 550:947-959.

Mailly P, Charpier S, Mahon S, Menetrey S, Thierry AM, Glowinski J, Deniau JM (2001) Dendritic arborizations of the rat substantia nigra pars reticulata neurons: spatial organization and relation to the lamellar compartmentation of striato-nigral projections. J Neurosci 21:6874-6888.

Mailly P, Charpier S, Menetrey A, Deniau JM (2003) Three-dimensional organization of the recurrent axon collateral network of the substantia nigra pars reticulata neurons in the rat. J Neurosci 23:5247-5257.

Marescaux C, Vergnes M, Depaulis A (1992) Genetic absence epilepsy in rats from Strasbourg-a review. J Neural Transm Suppl 35:37-69.

Maurice N, Deniau JM, Glowinski J, Thierry AM (1998) Relationships between the prefrontal cortex and the basal ganglia in the rat: physiology of the corticosubthalamic circuits. J Neurosci 18:9539-9546.
Maurice N, Thierry AM, Glowinski J, Deniau JM (2003) Spontaneous and evoked activity of substantia nigra pars reticulata neurons during highfrequency stimulation of the subthalamic nucleus. J Neurosci 23:9929-9936.

Migliore M, Shepherd GM (2002) Emerging rules for the distributions of active dendritic conductances. Nat Rev Neurosci 3:362-370.

Nambu A, Tokuno H, Hamada I, Kita H, Imanishi M, Akazawa T, Ikeuchi Y, Hasegawa N (2000) Excitatory cortical inputs to pallidal neurons via the subthalamic nucleus in the monkey. J Neurophysiol 84:289-300.

Neafsey EJ, Bold EL, Hass G, Hurley-Gius KM, Quirk G, Sievert CF, Terreberry RR (1986) The organization of the rat motor cortex: a microstimulation mapping study. Brain Res 396:77-96.

Orieux G, Francois C, Feger J, Hirsch EC (2002) Consequences of dopaminergic denervation on the metabolic activity of the cortical neurons projecting to the subthalamic nucleus in the rat. J Neurosci 22:8762-8770.

Panayiotopoulos CP (1997) Absences epilepsies. In: Epilepsy: a comprehensive textbook (Engel Jr J, Pedley TA, eds), pp 2327-2346. Philadelphia: Lippincott-Raven.

Paxinos G, Watson C (1986) The rat brain in stereotaxic coordinates, Ed 2. London: Academic.

Pinault D (1996) A novel single-cell staining procedure performed in vivo under electrophysiological control: morpho-functional features of juxtacellularly labeled thalamic cells and other central neurons with biocytin or Neurobiotin. J Neurosci Methods 65:113-136.

Pinault D (2003) Cellular interactions in the rat somatosensory thalamocortical system during normal and epileptic 5-9 Hz oscillations. J Physiol (Lond) 552:881-905.

Pinault D, Lereshe N, Charpier S, Deniau JM, Marescaux C, Vergnes M, Crunelli V (1998) Intracellular recordings in thalamic neurones during spike and waves discharges in rats with absence epilepsy. J Physiol (Lond) 509:449-456.

Plenz D, Kitai ST (1999) A basal ganglia pacemaker formed by the subthalamic nucleus and external globus pallidus. Nature 400:677-682.

Rall W (1969) Time constants and electrotonic length of membrane cylinders and neurons. Biophys J 9:1483-1508.

Reyes A (2001) Influence of dendritic conductances on the input-output properties of neurons. Annu Rev Neurosci 24:653-675.

Rouzaire-Dubois B, Scarnati E (1987) Pharmacological study of the cortical-induced excitation of subthalamic nucleus neurons in the rat: evidence for amino acids as putative neurotransmitters. Neuroscience 21:429-440.

Simons DJ, Carvell GE (1989) Thalamocortical response transformation in the rat vibrissa/barrel system. J Neurophysiol 61:311-330.

Slaght SJ, Leresche N, Deniau JM, Crunelli V, Charpier S (2002a) Activity of thalamic reticular neurons during spontaneous genetically determined spike and wave discharges. J Neurosci 22:2323-2334.

Slaght SJ, Paz T, Mahon S, Maurice N, Charpier S, Deniau JM (2002b) Functional organization of the circuits connecting the cerebral cortex and the basal ganglia: implications for the role of the basal ganglia in epilepsy. Epileptic Disord 4 [Suppl 3]:S9-S22.

Slaght SJ, Paz T, Chavez M, Deniau JM, Mahon S, Charpier S (2004) On the activity of the corticostriatal networks during spike-and-wave discharges in a genetic model of absence epilepsy. J Neurosci 24:6816-6825.

Song WJ, Baba Y, Otsuka T, Murakami F (2000) Characterization of $\mathrm{Ca}(2+)$ channels in rat subthalamic nucleus neurons. J Neurophysiol 84:2630-2637.

Steriade M (2004) Neocortical cell classes are flexible entities. Nat Rev Neurosci 5:121-134.

Timofeev I, Steriade M (2004) Neocortical seizures: initiation, development and cessation. Neuroscience 123:299-336.

Van Der Kooy D, Hattori T (1980) Single subthalamic nucleus neurons project to both the globus pallidus and substantia nigra in rat. J Comp Neurol 192:751-768.

Vercueil L, Benazzouz A, Deransart C, Bressand K, Marescaux C, Depaulis A, Benabid AL (1998) High-frequency stimulation of the subthalamic nucleus suppresses absence seizures in the rat: comparison with neurotoxic lesions. Epilepsy Res 31:39-46.

Williams D (1953) A study of thalamic and cortical rhythms in petit mal. Brain 76:56-69. 